Review

\title{
A Review of the Past and Current State of EROI Data
}

\author{
Ajay K. Gupta * and Charles A.S. Hall \\ Graduate Program in Environmental Science, College of Environmental Science and Forestry, \\ State University of New York, Syracuse, NY 13210, USA; E-Mails: chall@esf.edu \\ * Author to whom correspondence should be addressed; E-Mail: ajgupta@syr.edu; \\ Tel.: +1-315-470-6812; Fax: 315-470-6934.
}

Received: 11 June 2011; in revised form: 1 August 2011 / Accepted: 5 August 2011/ Published: 10 October 2011

\begin{abstract}
This is a review of the literature available on data for the EROI (prior to this special issue) of the following 12 sources of fuel/energy: oil and natural gas, coal, tar sands, shale oil, nuclear, wind, solar, hydropower, geothermal, wave/tidal and corn ethanol. Unfortunately, we found that few studies have been undertaken since the 1980s, and such as have been done are often marked more by advocacy than objectivity. The most recent summary of work and data on the EROI of fuels was conducted in the summer of 2007 at SUNY ESF and appeared on The Oil Drum website and in a readable summary by Richard Heinberg. This paper summarizes the findings of that study, and also those preceding and subsequent to it where available. It also summarizes issues raised by some concerning the findings of these studies and with the calculations within. While there are many who believe that such EROI studies are critical to understanding our financial and social future there seems to be very little interest by governments and industries in supporting this research or in using or promulgating such research as has been done. We view this as critical as our main fuels are progressively depleted and as we are faced with making extremely important decisions on a very meager analytical and data base, and with few scientists trained to cut through the reams of insufficiently analyzed energy advocacy saturating our media and the blogosphere.
\end{abstract}

Keywords: energy return on investment; EROI data; EROI of fuels 


\section{Introduction}

In the 1970's ecologist Charles Hall coined the term “Energy Return on Investment” (EROI), with originally a focus on migrating fish (e.g., Hall [1]). In the 1980s, Hall, working with Cutler Cleveland, Robert Kaufmann and others, extended the concept to seeking oil and other fuels. The concept had been around in the anthropological (e.g., Lee [2]), economic (e.g., Georgescu Roegan [3]), and ecological (e.g., Odum [4]) literature for some time, although it was expressed as "net energy." The difference is that EROI is the unit-less ratio of energy returned from an energy-gathering activity to the energy it takes to provide that energy, and net energy is the difference left over after the costs have been subtracted from the gains. Net energy can be useful but also misleading: it may be very large for a very large but poor quality resource (i.e., oil shales) that allow a large net from huge resources subject to slightly less huge costs. Alternately when used with EROI it can help assess a resource from both perspectives.

EROI has more utility, in our opinion, because it allows the ranking of fuels and an estimate of the changing in their ease of extraction over time, which can also be interpreted as the difference between the effects of technology (which would be expected to increase EROI) and depletion (which would be expected to decrease it). It also should be linked to the economic cost of fuels (See King and Hall, this volume). One important idea is that as this ratio approaches 1:1 the fuel is no longer useful to society (except for the presumably rare case where a low quality fuel is used to produce a higher quality fuel). The original papers on EROI (e.g., Hall and Cleveland [5], Cleveland et al. [6], Hall et al. [7]), were mostly received with interest, but that interest waned in the late 1980s and 1990s as fuel prices declined. More recently as energy prices have again been increasing the interest in EROI has again increased (e.g., Heinberg [8], many web sites). Additionally many papers on energy and emerging economic fields discuss this ratio and what it means to current and future economies (e.g., Hall and Klitgaard [9], Hall [10], Mearns [11], Day et al. [12], Hall et al. [13], Hall and Day [14], Murphy and Hall [15]). However, given the number of decades the concept of EROI has been around, only a small, although growing, body of work is available on the subject [15].

In fact, despite the growing interest in EROI, little new data are available today except for what is in this much-needed special issue. Most such efforts have been to refine the EROI for certain fuels, mostly petroleum based fuels, and to examine the utility of corn-based ethanol — which are discussed below - but there is very little information available in terms of a large body of work providing data on a range of inputs important to our economies. The first attempted synthesis was in a table in Cleveland et al. [6] and more comprehensively in a book by essentially the same authors [7]. In an effort to update the data in this book, a study was conducted by students of Hall at SUNY ESF in 2007 under a grant from the Santa Barbara Family Foundation (available on the oildrum.com), summarized by Heinberg [8]. What follows is a summary of the EROIs of the 12 fuels examined in that study, and updates with other data where available. The data presented in this special issue are considered relative to these earlier studies in the final paper in this special issue.

\section{EROI for Oil and Gas}

Oil and conventional natural gas are usually studied together because they often occur in the same fields, have overlapping production operations and data archiving. The SUNY ESF study was not able 
to update the earlier EROI numbers for oil and gas beyond one additional study by Cleveland [16]. This study gave values similar to those reported in the earlier Cleveland and Hall studies: The EROI for producing oil and gas was roughly 30:1 in the 1950s which declined irregularly to 20:1 in the 1970s and 11-18:1 in the mid 2000's. An additional finding of oil in these studies was that the EROI tended to decline when drilling rates were higher, and increase when drilling was relaxed. These two trends, a secular decline and a secondary response to drilling intensity together explained most (about 92 percent in one analysis) of the variability in oil production. There have now been updates to these analyses for the U.S. until the present issue (See Guilford et al., this volume). The first study for the EROI of global oil and gas resources appears to be Gagnon et al. [17].

Precise calculations on the energy inputs required by the global (or any) petroleum industry are difficult to produce due to limited data. Unfortunately, few countries make such information public or ensure quality control where available [8,17]. As a result, Gagnon et al. had to estimate energy costs by calculating the energy equivalent per dollar spent (i.e., the energy intensity) in the petroleum industry (or that portion publically traded) using various methods to estimate the energy intensity from fairly good data for the U.S. and the U.K. [17]. They found that about 20 MJ were used for each 2005 dollar spent for both countries, and concluded that global oil and gas EROI was approximately 26:1 in 1992, increased to 35:1 in 1999, and declined to 18:1 by 2006 (Figure 1). Thus the EROI for global oil and gas appeared to have a similar declining trend as the U.S. but was from 50 to 100 percent higher at any given time-which makes sense as the U.S. is more thoroughly exploited than the rest of the world. These authors also estimated through linear extrapolation that the EROI for global oil and conventional natural gas could reach 1:1 as soon as about 2022 given alternative input measurement methods (Figure 2). However, the authors also state that given historical EROI trends, the uncertainty for the exact date is large and a linear decline assumes an exponential rise in cost per unit output. An alternative would be a linear increase in cost per unit output which would result in an exponential decline of EROI and thus push back the break-even point. The authors note that although the EROI for gas is likely much higher than that for oil in most cases, due to the difference in energy costs for raising the fuel in a well, EROI is often represented as an average of both fuels for a given field.

We are not aware of any peer-reviewed published studies available on EROI on non-conventional natural gas to date. The unpublished 2007 SUNY ESF study did estimate the EROI for U.S. domestic gas by analyzing data from a random sample of 100 wells in Indiana County, Pennsylvania in a "bottom-up" EROI calculation [18]. The authors estimated that in 2005 the EROI for a gas field in the U.S. is 10:1 although new analysis (in this special issue) by Sell et al. gives a considerably higher estimate. Heinberg predicts that these sources will have lower EROIs than conventional gas and as they take over market share in the global energy matrix, the EROI for natural gas could decline dramatically, but we are desperately in need of real analyses on this subject using solid data [8]. 
Figure 1. All known EROIs for oil and gas production as per about 2008 [17]. These data imply that EROI is declining over time except during periods of relaxed drilling effort, that quality corrections decrease EROI, and that the EROI for global oil and gas is higher than for the U.S. (a) The triangle is a crude estimate for the EROI of U.S. oil and gas discoveries in 1930 [6]; (b) Crosses are Cleveland et al.'s estimates for the EROI for production in the U.S. This paper also gives values for discoveries that are mostly about half those of production, implying a very large decline since 1930 [6]; (c) The dashed line is Cleveland's assessment of U.S. EROI for production including a correction for quality (i.e., for the production of higher quality electricity used in production) [16]; and (d) Global oil and gas EROI [17].

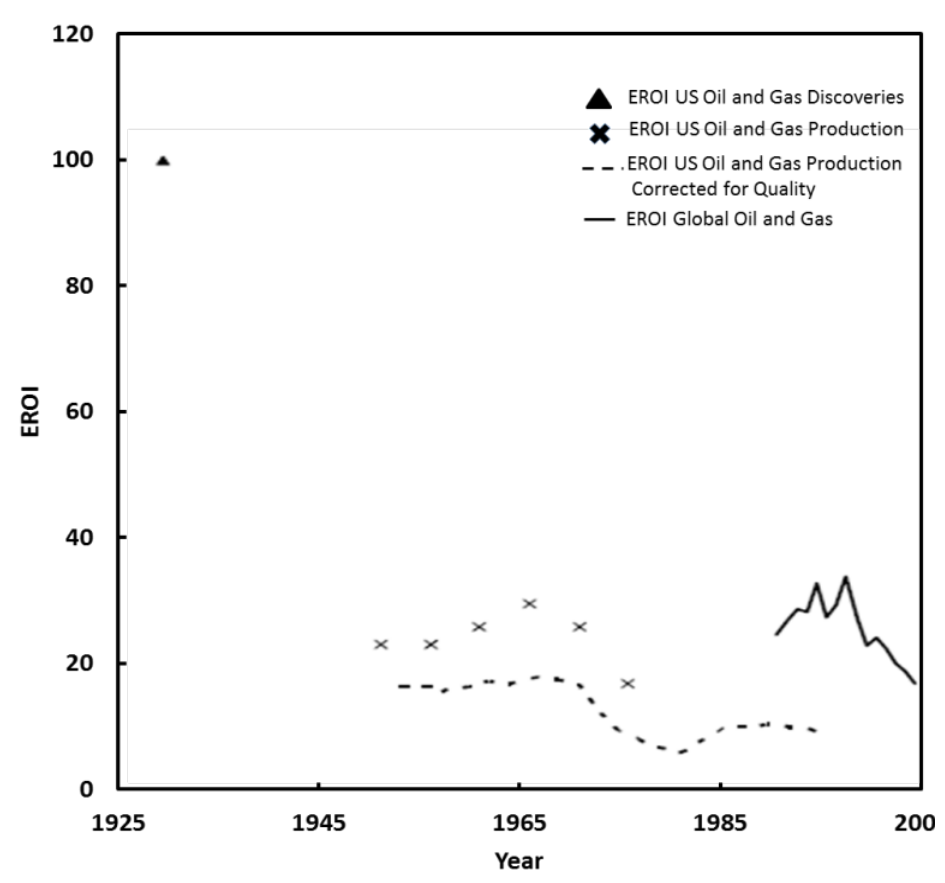

The 2007 SUNY ESF study also estimated the EROI of imported oil to the U.S. This is done differently from a conventional EROI analysis and is different for each importing entity. For the U.S. the EROI of imported oil (crude and refined) is measured not simply as the energy required to bring the oil to the surface as input, or that to transport it to the recipient, but rather as the energy cost of goods and services that must be used to generate the items of trade necessary to generate the foreign exchange (dollars) used to purchase the petroleum, that is to trade for that oil in energy for energy units [19]. Such a calculation also requires the use of energy intensities to convert dollars to energy units. Therefore the authors are again forced to assume that a cost in dollars reflects the cost in energy. This is especially relevant to the subject of imported fuel since the EROI can change dramatically as the relation between the price of oil and the goods and services exported over seas go up and down. A more explicit energy cost was undertaken by Kaufmann in 1986 [7], where he was able to use more specific energy intensities for the major items exported (e.g., the energy cost to produce a dollar's worth of wheat). This was possible because at that time the U.S. federal government maintained more detailed records on the energy used for specific sectors of the economy, and researchers at the University of Illinois were able to derive much more explicit energy intensities (e.g., Hannon [20]). When the values derived in the Palcher et al. study were compared to Kaufmann's 
more explicit, and presumably more accurate studies, the values had a similar pattern over time and were usually quite similar, except for 1969-1974, when the Palcher et al. estimates were about 50 percent higher than Kaufmann’s. The reasons for this discrepancy are unknown (Figure 3).

Figure 2. A linear extrapolation of trends in EROI for global oil and gas production [17]. (a) Also shown are linear extrapolations of the steepest and most gradual trends in EROI resulting from different methods of calculating energy input (dashed lines). These were obtained by calculating energy input using energy intensity defined as energy use per real (2005) dollar of gross product of the oil and gas extraction sector with a unique energy intensity for each year (steep slope), and using the average energy intensity over all years (gradual slope).

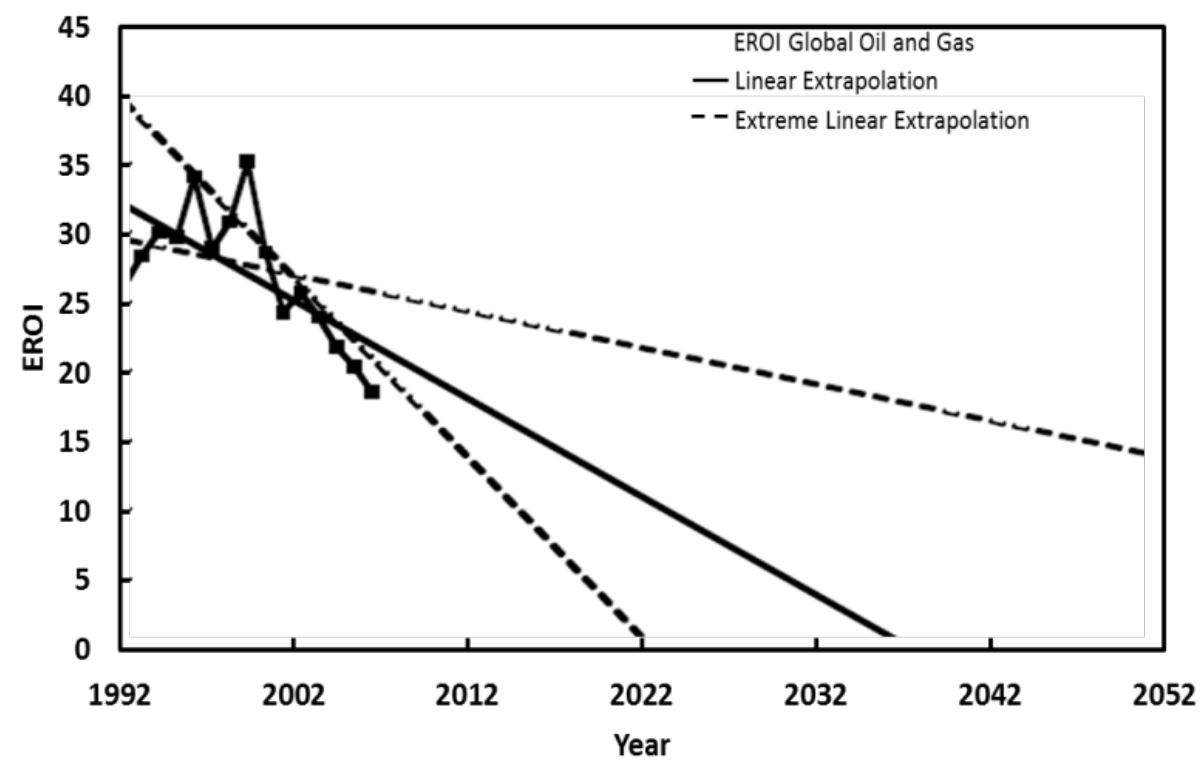

Figure 3. EROI for Imported Crude Oil to the U.S. [19]

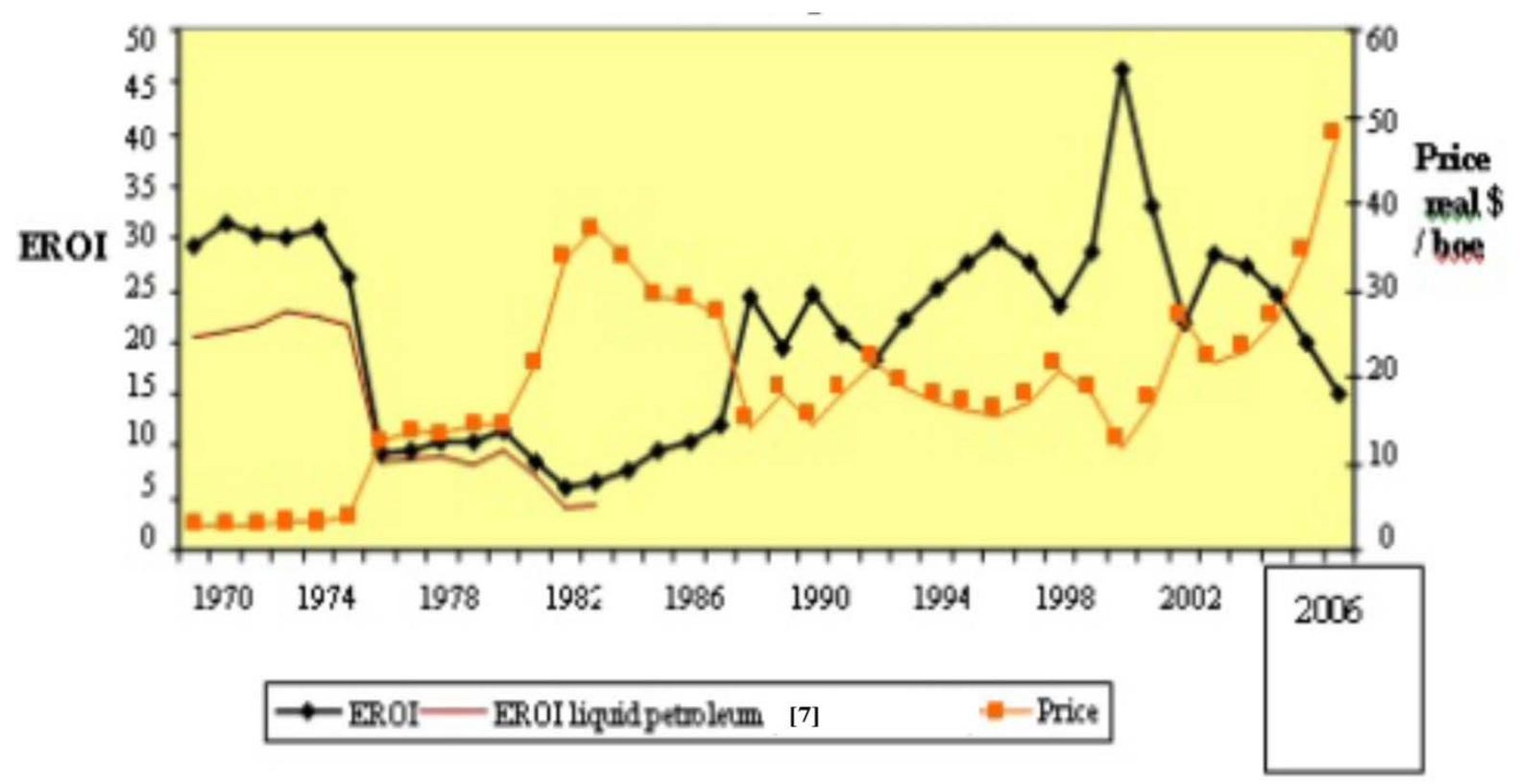


The authors of this EROI study note that they exclude the interest paid on debts to purchase foreign oil. Including that cost presumably would decrease EROI. As can be expected, the EROI of imported oil to the U.S. is mostly a reflection of the price of oil relative to the price of general goods and services at that time (Figure 3).

\section{EROI for Coal}

Unfortunately, the 2007 SUNY ESF study did not include coal. However, there are previous studies that give some values. The first of these was conducted by Hall and Cleveland [5] and Hall et al. [7]. They calculated the EROI of U.S. coal including estimates of capital structure, labor, and transportation from 1930 to the late 1970's and found that it was relatively constant at approximately 30:1 until the 1960's when it increased to approximately 35:1, and then fell during the 1970's to less than 20:1. The rise in EROI during the 1960's is attributed to increased extraction efficiency as production shifted to Western surface coal, whereas the drop in EROI during the 1970's is attributed mostly to a decline in the quality of coal being mined in the U.S.

A subsequent study by Cleveland yielded similar patterns over time although the EROIs are much higher [21]. Cleveland calculated the EROI of coal using thermal equivalents, and also quality-corrected values. His thermal equivalent values for EROI are approximately 3 times higher than those of Hall et al. [7], perhaps due to a difference in energy accounting methods and system boundaries. Cleveland found that the EROI of U.S. coal fell from about 100:1 during the 1960's to approximately 50:1 and then began to increase to higher than approximately 70:1 by 1987 . The quality-corrected values are 4 times lower. There is no information on the EROI of coal beyond 1987 that we know of. However some assumptions can be made. For the U.S. there are forces driving down the EROI into the future. Bituminous coal hit its production peak in about 1992 and has been gradually declining in quality (BTUs per ton) since the 1950's [7]. Also, increased environmental regulations on the industry would have negative impacts on EROI. Forces driving the EROI of coal up include the growing trend of moving from underground mining to surface mining, and other gains in extraction efficiencies. It is not clear whether over time the decline in resource quality would be greater or less than the increased impact of technology. A problem here, too, is a great decline in the quality of data maintenance by the federal government.

\section{EROI for Tar Sands}

Tar sands, or oil sands, consist of bitumen embedded in sand or clay. It is similar to conventional oil except that it was formed without a geological cap, and thus is not sufficiently "cooked” geologically. It can be liquefied underground through the injection of steam, or mined at the surface, and then processed into liquid fuel called syncrude. The largest producers of syncrude are Canada and Venezuela. The reserves are enormous, but the extraction rate is limited by environmental and other constraints.

The 2007 SUNY ESF study used a "bottom up" approach to calculate the EROI [22]. The calculation is slightly different from other fuels since the source of fuel for syncrude production is the syncrude itself. The system boundaries are limited to the extraction, separation, and upgrading processes. Indirect costs, labor and environmental considerations were calculated by converting dollar costs per barrel to energy costs. 
The authors calculate an EROI of about 6:1 that is based mostly upon the direct energy costs of producing syncrude. Including indirect inputs reduced the EROI to about 5:1, and including the energy equivalent of environmental impacts and labor had only a marginal effect. Previous studies reported by Herweyer and Gupta calculated EROIs lower than their results, in the vicinity of 3:1. Reasons for the differences include different energy accounting methods or data, and most likely, gains in process efficiency realized since the earlier studies. Also, syncrude production is not only very energy intensive, but also a large consumer of water, which could also have a negative impact on EROI.

In 2009 a preliminary study posted on The Oil Drum calculated the EROI of producing syncrude from the new Toe to Heel Air Injection (THAI) method as about 9:1, with a range of 3.3-56:1 given different assumptions on the relevance of inputs [23]. Murphy's best estimate of 9:1 is higher than that for the syncrude production processes considered previously by Herweyer and Gupta. This is most likely due to the smaller quantities of natural gas and water necessary in the THAI process.

\section{EROI for Shale Oil}

Shale oil is similar to tar sands in some ways-both are very low quality resources of petroleum. Whereas tar sands are bitumen surrounding a substrate such as clay or sand with a layer of water in between, shale oil consists of kerogen fused directly to the substrate itself. If tar sands can be thought of as "undercooked" petroleum, shale is oil is that which is "overcooked." As it is more difficult to separate the kerogen from a substrate than to separate bitumen from water, it is expected that the EROI for shale oil should be lower than that of tars sands simply from a chemical point of view.

The SUNY ESF study did not calculate the EROI of shale oil. Instead it reviewed a number of studies from 1975 up to 2007 which had made some kind of EROI or net energy assessment [24]. Most of these studies gave EROIs for shale oil from 1.5-4:1. A few earlier studies suggested an EROI of 7:1 to 13:1. More recent analyses of the "Shell technique," an approach meant to be relatively environmentally benign and currently in operation, gave estimates of about 3-4:1, although since most of the inputs are electricity and the output is oil one might think that a quality-corrected analysis would lead to near 1:1 [25]. In general, these numbers are in the same range and with the same degree of uncertainty as tar sands. Also, both are unique in that the resource can be used to fuel its own extraction. Although the authors suggest that other technologies are available to producing shale oil, there are no other field tested operations available to calculate EROI.

\section{EROI for Nuclear}

Nuclear power is the use of controlled fission reactions for the purpose of producing electricity. There are currently 439 commercial nuclear power plants worldwide generally using variations of the same technology [8]. The SUNY ESF study summarized the EROI of nuclear power from previous studies [26]. The review concludes that the most reliable information is still from Hall et al.'s [7] summary of an EROI of about 5-8:1 (with a large part of the variability depending upon whether the electricity is corrected for quality), and that the newer studies appear either too optimistic or pessimistic with reported EROIs of up to almost 60:1, to as low as even less than 1:1. Clearly with reactors operating for longer periods of time, with the possibility of serious uranium shortages with 
larger use, and with the new considerations of the Japanese reactor accidents due to the earthquake and subsequent tsunami new calculations are needed.

The authors note that the differences in EROI can sometimes be attributed to differences in system boundaries and technologies. However, overall there is a lack of empirical information on the subject. The three major drivers of nuclear EROI are the enormous upfront costs of capital required, environmental costs, and the grade of uranium ore available. At present, much of the ore is secured from dismantled warheads; a return to seriously depleted geological deposits could constitute a decrease in EROI in the future. On the other hand there are possible new, but untested, technologies using smaller reactors or even thorium that might lead to safer and higher EROI reactors.

\section{EROI for Wind}

Wind energy is one of the fastest growing renewable energies in the world today, although it still represents far less than one percent of global or U.S. energy use. Since it is renewable energy, EROI is not calculated the same as for finite resources. The energy cost for such renewable systems is mostly the very large capital cost per unit output and the backup systems needed, for two thirds of the time the wind is not blowing. As a result, the input for the EROI equation is mostly upfront, and the return over the lifetime of the system-which largely is not known well. For renewable resources a slightly different type of EROI is often used, the "energy pay back time” (EPBT). EPBT is the time it takes for the system to generate the same amount of energy that went into creating, maintaining, and disposing of it, and so the boundaries used to define the EPBT are those incorporated into the EROI.

Although the SUNY ESF study did not calculate EROI for wind they were able to use a recent "meta-analysis" study by Cleveland and Kubiszewski [27]. In this study the authors examined 112 turbines from 41 analyses of both conceptual and operational nature. The system boundaries included the manufacture of components, transportation of components to the construction site, the construction of the facility itself, operation and maintenance over the lifetime of the facility, overhead, possible grid connection costs, and decommissioning where possible, however not all studies include the same scope of analysis. The authors concluded that the average EROI for all systems studied is 24.6:1 and that for all operational studies is 18.1:1. The operational studies provide lower EROIs because the simulations run in conceptual models appear to assume conditions to be more favorable than actually experienced on the ground.

The authors found that the EROI tends to increase with the size of the turbine. They conclude that there are three reasons for this. First, that smaller turbines are of older design and can be less efficient, so despite a larger initial capital investment larger systems compensate with larger energy outputs; second that larger models have larger rotor diameters so they can operate at lower wind speeds and capture more wind energy at higher efficiencies year round; and finally because of their size, larger models are taller and can take advantage of the higher wind speeds farther above ground.

Aspects of wind energy which can lower the EROI include the location of manufacture and installation but have greater construction and maintenance costs as they can add to the initial capital investment of a wind turbine or limit the use of recycled materials. Also, energy storage and grid connection dynamics could potentially reduce EROI where applicable. Finally off shore systems would experience more reliable winds but have greater maintenance costs associated with them. 


\section{EROI for Photovoltaics}

The use of Solar photovoltaics (PV) are increasing almost as rapidly as wind systems, although they too represent far less than 1 percent of the energy used by the U.S. or the world. Similarly, they are a renewable source of energy and thus the EROIs are also calculated using the same idea. Although there are very few studies which perform "bottom up" analysis of the PV systems we are familiar with today, we can calculate the EROI by dividing the lifetime of a module by its energy payback time (EPBT). Like wind turbines, PV EPBT can vary depending on the location of production and installation. It can also be affected by the materials used to make the modules, and the efficiency with which it operates - especially under extreme temperatures.

The SUNY ESF study looked at a number of life cycle analyses from 2000 to 2008 on a range of PV systems to determine system lifetimes and EPBT, and subsequently calculated EROI [28]. The system lifetimes and EPBT are typically modeled as opposed to empirically measured. As a result, EROI is usually presented as a range. Typically the author found most operational systems to have an EROI of approximately 3-10:1. The thin-film modules considered had an EROI of approximately 6:1 whereas some theoretical modules, including a 100MW very large scale PV installation reached or exceeded 20:1. A subsequent study by Kubiszewski et al. [29] reviewed 51 systems from 13 analyses and calculated similarly an average EROI of 6.56:1. Much promotional literature gives higher estimates but we are unable to validate their claims. A book in preparation (Prieto and Hall [30]) examines actual energy costs and gains from a series of collectors in Spain and suggests that actual operating EROIs might be considerably less than promoters suggest.

Factors contributing to the increase of EROI include increasing efficiency in production, increasing efficiency of the module, and using materials that are less energy intensive than those available today. Factors contributing to lower EROI include lower ore grades of rare metals used in production (from either depletion in the ground or competition from other industries) and lower than projected lifetimes and efficiencies, problems with energy storage, and intermittence.

The SUNY ESF study also examined passive solar heating and cooling for buildings [31]. A passive solar building is one which captures and optimizes the heat and light available from the sun without the use of any collectors, pumps or mechanical parts, but by design. Unfortunately, passive solar is incredibly site specific and thus calculating an EROI can be very difficult. However, the author does explain how a calculation could be achieved by performing the same operations as those for other renewable forms of energy-lifetime of structure divided by the EPBT. The EROI for a well designed building certainly has the potential to be quite favorable.

\section{EROI for Hydropower}

Hydropower plants vary greatly in size and scope, and thus so does the energy output and necessary inputs required to build and maintain facilities. Large scale hydropower projects, usually involving reservoirs, are the best researched. Although there is much room for further hydropower installation worldwide, there are only limited areas in the U.S. for further development. For hydropower, the EROI is calculated the same as other renewable sources of energy, where the total energy output over the lifetime of the station is divided by the energy costs of creating and maintaining it. It is unclear if decommissioning sites are part of the analysis, which would lower the EROI. 
The SUNY ESF study reviewed previous studies on specific installations [32]. EROI figures examined by the author ranged from 11.2-267:1 due to the extreme variability of geography and technology. The author noted that environmental and social costs, which can be substantial, are not incorporated in the numbers. Since all these costs and gains are site sensitive, it is clear that determining an overall EROI for hydropower would be meaningless and that each project would need to be examined separately. Yet, given the range of EROIs in the study, it seems that hydropower, where available, is often a good energy return on investment.

\section{EROI for Geothermal}

Geothermal energy uses the heat within the Earth to do work by transferring the heat to a gas such as steam, or a liquid. This can be used to produce electricity or heat for buildings etc. The best suited sites are near plate boundaries and as such are not available to everyone. Currently, only hydrothermal resources are being utilized for commercial energy. These are where heat is transferred to groundwater at drillable depths. Enhanced geothermal systems also known as Hot Dry Rock (HDR) are thought to be able to exploit heat at greater underground depths where there is no groundwater although there are none in commercial use. Another theoretical system called geopressured geothermal could provide thermal energy from hot brine, mechanical energy from highly pressured fluid, and chemical energy from confined methane, but the specifics for such systems are unknown. In fact there is no consensus on resource base estimates for geothermal energy.

The SUNY ESF study calculated the EROI for HDR geothermal systems and reviewed previous studies on hydrothermal resources from 1975-1991 [33]. The EROI for electricity generation from hydrothermal resources was reported with a range of 2-13:1. Corrected for quality as an electricity source, this is recalculated as approximately 6-39:1. Some theoretical EROI values have been calculated for HDR ranging from 1.9-13:1 or 5.7-39:1 when quality corrected, and for geopressured systems with a range of 2.9-17.6:1. The author attributes the large ranges to a lack of a unified methodology for EROI analysis and disagreements about system boundaries, quality-correction, and future expectations. No EROI values of geothermal direct use were found. Energy can be extracted from normal soils and ground water with an EROI of about 5:1, although the input is electricity and the output heat so the quality corrected output may not be very high.

\section{EROI for Wave/Tidal}

There is very little information available on wave or tidal energy due to its fledgling state in commercial application. Despite ongoing research and projects, attaining an EROI on wave or tidal energy systems is very difficult due to the small scale of the industry and also the fact that these systems are very site specific. The SUNY ESF study estimated that one wave energy project could have an EROI of approximately 15:1 [34]. This number was estimated based on a life cycle assessment of the Pelamis off-shore device currently deployed outside of Portugal. A problem is that it is difficult to maintain many devices when large storms occur. 


\section{EROI for Corn Ethanol}

The debate over the EROI for corn ethanol is probably the most documented of all the energy sources presented here. Most of the often rancorous literature has been about whether corn ethanol requires more energy than it uses (i.e., EROI of $<1: 1$ ) or whether it is positive, if low. The EROI of the numerous studies available on the subject range from approximately $0.8: 1$ to $1.3-2: 1$ [35]. The difference in values is mostly attributed to boundaries used and energy quality issues. This issue is explored in more detail in the paper by Hall, Dale and Pimentel in this special Journal issue.

In one recent study, Murphy et al. demonstrate that it cannot be statistically determined if the EROI for corn ethanol is above or below zero with any confidence, and that the largest impact on EROI is from co-products of the energy producing system, not yields of corn [35]. They also state that when Iowa is used as a benchmark for growing conditions and expected yields, the EROI is likely to be on the lower side of the scale given that Iowa represents the best conditions in the U.S. These authors conclude that the energy gains, if any, from corn ethanol are negligible without co-product credit.

\section{Discussion}

There has been a surprisingly small amount of work done in the field of EROI calculation despite its obvious uses and age. From this review it can be inferred that there are only a handful of people seriously working on the issues related to energy return on investment. As such it does not come as a surprise that the information is scarce and unrefined at best-although perhaps not in the case of ethanol. Additionally there is a great deal of rather misleading material presented in the media and very few with the training to cut through the fog or deliberate lies. We have presented what we believe to be virtually all of the data available until this special issue.

Since the 1980's the energy information required to make such calculations have become even scarcer, with the possible exception of some European life cycle analyses. This is a terrible state of affairs given the massive changes in our energy situation unfolding daily. We need to make enormously important decisions but do not have the studies, the data or the trained personnel to do so. Thus we are left principally with poorly informed politicians, industry advocacy and a blind but misguided faith in market solutions to make critical decisions about how to invest our quite limited remaining high quality energy resources. Our major scientific funding agencies such as the National Science Foundation and even the Department of Energy have been criminally negligent by avoiding any serious programs to undertake proper EROI, environmental effects, or other studies, while our federal energy data collections degrade year by year under misguided cost cutting and free market policies.

As stated by Murphy and Hall [15], there needs to be a concerted effort to make energy information more transparent to the people so we can better understand what we are doing and where we are going. Given what we do know, it seems that the EROI of the fuels we depend on most are in decline; whereas the EROI for those fuels we hope to replace them with are lower than we have enjoyed in the past. This leads one to believe that the current rates of energy consumption per capita we are experiencing are in no way sustainable in the long run. At best, the renewable energies we look toward may only cushion this decline. 


\section{Acknowledgments}

We would like to acknowledge the help of our reviewers in refining the information available here. Specifically we would like to thank Robert Kaufmann for his insights into extrapolating EROI into the future. We would also like to thank the members of the SUNY ESF research team for undertaking the task of accumulating much of this scarce information. The original results are reported in The Oil Drum website (www.theoildrum.com) and in a summary by Richard Heinberg. Finally we would like to thank the Santa-Barbara Family Foundation for providing the funding for that research, and the UK Department for International Development (DFID) and Tullet Prebon for recent support.

\section{Conflict of Interest}

The authors declare no conflict of interest.

\section{References and Notes}

1. Hall, C.A.S. Migration and metabolism in a temperate stream ecosystem. Ecology 1972, 53, 585-604.

2. Lee, R. Kung bushman subsistence: An input-output analysis. Environ. Cult. Behav. 1969, 47-79.

3. Georgescu-Roegen, N. Energy and economic myths. South. Econ. J. 1975, 41, 347-381.

4. Odum, H.T. Environment, Power and Society; Wiley InterScience: New York, NY, USA, 1973.

5. Hall, C.; Cleveland, C. Petroleum drilling and production in the United States: Yield per effort and net energy analysis. Science 1981, 211, 576-579.

6. Cleveland, C.J.; Costanza, R.; Hall, C.A.S.; Kaufmann, R. Energy and the U.S. economy: A biophysical perspective. Science 1984, 225, 890-897.

7. Hall, C.; Cleveland, C.; Kaufmann, R. Energy and Resource Quality: The Ecology of the Economic Process; Wiley-InterScience: New York, NY, USA, 1986.

8. Heinberg, R. Searching for a Miracle: Net energy limits and the Fate of Industrial Societies. A Joint Project of the International Forum on Globalization and Post Carbon Institute. In False Solutions Series \#4; Post Carbon Institute: Santa Rosa, USA, 2009.

9. Hall, C.; Klitgaard, K. The need for a new, Biophysically-based paradigm in economics for the second half of the age of oil. Int. J. Transdiscipl. Res. 2006, 1, 4-22.

10. Hall, C. Why EROI Matters (Part 1 of 6). The Oil Drum, 2008, Available online: http://www.theoildrum.com/node/3786 (accessed on 1 June 2011).

11. Mearns, E. Oil production and energy return on investment (EROI). www.sindark.com: Ottawa, Canada, 2008; Available online: http://www.sindark.com/2008/08/23/oil-production-and-energyreturn-on-investment-eroi/ (accessed on 1 June 2011).

12. Day, J.W., Jr.; Hall, C.A.; Yanez-Arancibia, A.; Pimentel, D.; Marti, C.I.; Mitch, W.J. Ecology in times of scarcity. BioScience 2009, 59, 321-331.

13. Hall, C.A.S.; Balogh, S.; Murphy, D.J.R. What is the minimum EROI that a sustainable society must have? Energies 2009, 2, 25-47.

14. Hall, C.A.S.; Day, J.W., Jr. Revisiting the limits to growth after peak oil. Am. Sci. 2009, 97, 230-237.

15. Murphy, D.J.R.; Hall, C.A.S. Year in review_EROI or energy return on (energy) invested. Ann. N.Y. Acad. Sci. 2010, 1185, 102-118. 
16. Cleveland, C.J. Net energy from oil and gas extraction in the United States, 1954-1997. Energy 2005, 30, 769-782.

17. Gagnon, N.; Hall, C.A.S.; Brinker, L. A preliminary investigation of energy return on energy investment for global oil and gas production. Energies 2009, 2, 490-503.

18. Button, S.; Sell, B. Appendix C: Natural Gas: Potential, EROI and Social and Environmental Impacts. The Oil Drum, 2008; Available online: http://www.theoildrum.com/node/3810 (accessed on 1 June 2011).

19. Palcher, S.; Herweyer, M.C.; Hall, C.A.S. Appendix B: Crude and refined oil imported to the United States. The Oil Drum, 2008; Available online: http://www.theoildrum.com/ node/3810 (accessed on 1 June 2011).

20. Hannon, B. Analysis of the energy cost of economic activities: 1963-2000. 1982, 6, 249-278.

21. Cleveland, C.J. Energy quality and energy surplus in the extraction of fossil fuels in the U.S. Ecol. Econ. 1992, 6, 139-162.

22. Herweyer, M.C.; Gupta, A.K. Appendix D: Tar Sands/Oil Sands. The Oil Drum, 2008; Available online: http://www.theoildrum.com/node/3839 (accessed on 1 June 2011).

23. Murphy, D.J.R. EROI Update: Preliminary Results using Toe-to-Heel Air Injection. The Oil Drum, 2009; Available online: http://netenergy.theoildrum.com/node/5183 (accessed on 1 June 2011).

24. Gupta, A.K.; Herweyer, M.C.; Hall, C.A.S. Appendix E: Oil Shale: Potential, EROI and Social and Environmental Impacts. The Oil Drum, 2008; Available online: http://www.theoildrum.com/node/3839 (accessed on 1 June 2011).

25. Shell Frontier Oil and Gas. Oil Shale Test Project. Oil Shale Research and Development Project 2006-02-15. Shell Frontier Oil and Gas Inc.: Boulder, USA, 2006; Available online: www.blm.gov/pgdata/etc/medialib/blm/co/field_offices/white_river_field/oil_shale.Par.79837.File .dat/OSTPlanofOperations.pdf (accessed on 1 June 2011).

26. Powers, R. Appendix F: Nuclear Electricity: Potential, EROI and Social and Environmental Impacts. The Oil Drum, 2008; Available online: http://www.theoildrum.com/node/3877 (accessed on 1 June 2011).

27. Cleveland, C.J.; Kubiszewski, I. Energy Return on Investment (EROI) for Wind Energy. Publisher: The Oil Drum, 2008; Available online: http://www.theoildrum.com/node/1863 (accessed on 1 June 2011).

28. Gupta, A.K. The Energy Return of (Industrial) Solar - Passive Solar, PV, Wind and Hydro (\#5 of 6): Appendix G-2. The Oil Drum, 2008; Available online: http://www.theoildrum.com/ node/3910 (accessed on 1 June 2011).

29. Kubiszewski, I.; Cleveland, C.; Szostak, R. Energy return on investment (EROI) for photovoltaic energy. The Encyclopedia of Earth: Boston, USA, 2009; Available online: http://www.eoearth.org/article/Energy_return_on_investment_(EROI)_for_photovoltaic_energy (accessed on 1 June 2011).

30. Prieto, P.; Hall, C.A.S. Net Energy from Photovoltaics in the Spanish Electricity Grid; Springer: New York, NY, USA, In Preparation.

31. Giermek, K. The Energy Return of (Industrial) Solar-Passive Solar, PV, Wind and Hydro (\#5 of 6): Appendix G-1. The Oil Drum, 2008; Available online: http://www.theoildrum.com/ node/3910 (accessed on 1 June 2011). 
32. Schoenberg, B. The Energy Return of (Industrial) Solar-Passive Solar, PV, Wind and Hydro (5 of 6): Appendix G. The Oil Drum, 2008; Available online: http://www.theoildrum.com/node/3910 (accessed online 1 June 2011).

33. Halloran, D. Appendix H: Geothermal Energy Summary. The Oil Drum, 2008; Available online: http://www.theoildrum.com/node/3949 (accessed on 1 June 2011).

34. Halloran, D. Appendix I: Wave Energy: Potential, EROI, and Social and Environmental Impacts. The Oil Drum, 2008; Available online: http://www.theoildrum.com/node/3949 (accessed on 1 June 2011).

35. Murphy, D.J.R.; Hall, C.A.S.; Powers, B. New perspectives on the energy return on (energy) investment (EROI) of corn ethanol. Environ. Dev. Sustain. 2010, 13, 179-202.

(C) 2011 by the authors; licensee MDPI, Basel, Switzerland. This article is an open access article distributed under the terms and conditions of the Creative Commons Attribution license (http://creativecommons.org/licenses/by/3.0/). 